\title{
Lessons and new directions for extended cognition from social and personality psychology
}

\section{Joshua August Skorburg}

To cite this article: Joshua August Skorburg (2017): Lessons and new directions for extended cognition from social and personality psychology, Philosophical Psychology

To link to this article: http://dx.doi.org/10.1080/09515089.2017.1282606

曲冓 Published online: 31 Jan 2017.

Submit your article to this journal $\asymp$

a)

View related articles

View Crossmark data $\complement \pi$ 


\title{
Lessons and new directions for extended cognition from social and personality psychology
}

\author{
Joshua August Skorburg \\ Department of Philosophy, University of Oregon, Eugene, OR, USA
}

\begin{abstract}
This paper aims to expand the range of empirical work relevant to the extended cognition debates. First, I trace the historical development of the person-situation debate in social and personality psychology and the extended cognition debate in the philosophy of mind. Next, I highlight some instructive similarities between the two and consider possible objections to my comparison. I then argue that the resolution of the person-situation debate in terms of interactionism lends support for an analogously interactionist conception of extended cognition. I argue that this interactionism might necessitate a shift away from the dominant agent-artifact paradigm toward an agent-agent paradigm. If this is right, then social and personality psychology - the discipline(s) that developed from the person-situation debate-opens a whole new range of empirical considerations for extended cognition theorists which align with Clark \& Chalmers original vision of agents themselves as spread into the world.
\end{abstract}

\section{ARTICLE HISTORY}

Received 13 May 2016 Accepted 4 January 2017

\section{KEYWORDS}

Extended cognition; extended mind; interactionism; personality psychology; situationism; social psychology

\section{Introduction}

Wagman and Chemero (2014) point out that proponents and opponents of extended cognition both agree that the questions about extended cognitive processes are empirical ones (p. 105). I concur, and in this paper I will attempt to expand the range of empirical work that is relevant to the extended cognition debate beyond the usual suspects (e.g., Ballard, Hayhoe, Pook, \& Rao, 1997; Brooks, 1991; Kirsh \& Maglio, 1994) and into the domain of social and personality psychology.

I will argue that there are instructive similarities between the development of the person-situation debate in social and personality psychology and the development of the extended cognition debate in the philosophy of mind. The payoff is twofold: (1) insofar as my comparison holds, the resolution of the person-situation debate can provide (indirect) evidence for the plausibility of certain formulations 
of extended cognition over others, which will, in turn, (2) open up a new range of empirical considerations for extended cognition theorists in social and personality psychology.

Here's the plan for the paper: In section 1, I trace the historical development of the person-situation debate (section 1.1) and the extended cognition debate (section 1.2). In section 2 I highlight some instructive similarities between the two (section 2.1) and consider possible objections to my comparison (section 2.2). In section 3, I explore the implications of the person-situation/extended cognition comparison: I argue that if the comparison holds, then the resolution of the person-situation debate in terms of interactionism lends support for analogously interactionist conceptions of extended cognition (section 3.1). I then suggest that interactionist conceptions of extended cognition might necessitate a shift away from the dominant agent-artifact paradigm toward the kind of agentagent paradigm operative, for example, in research on romantic relationships in personality psychology (section 3.2).

\section{Historical narratives}

In this first part of the paper, I trace the historical developments of the person-situation debate in social and personality psychology (section 1.1) and the extended cognition debate in the philosophy of mind (section 1.2). Both traditions are rich and varied, and so my telling cannot but be idiosyncratic and selective. My aim here is simply to offer a coherent story about the evolution of each tradition. I will then go on to identify instructive similarities between these stories (section 2) and examine what follows from them (section 3 ).

\subsection{The person-situation debate}

Many introductory courses and textbooks in social psychology begin with a salutatory reference to Lewin's (1936/2015) equation: $\mathrm{B}=f(\mathrm{P}, \mathrm{E})$, where " $\mathrm{B}$ " is behavior, " $\mathrm{P}$ " is the person and " $\mathrm{E}$ " is the environment, such that behavior is a function of the person and the environment. When written in this way, the comma indicates agnosticism on the precise nature of the relationship between person and environment. On one reading, the comma separates two independent entities, which is to say that the effect of some aspect of personality on behavior is the same regardless of the environment or situation (I use "environment" and "situation" interchangeably), and the effect of some aspect of the situation on behavior is the same regardless of the person. Kihlstrom (2013) notes that this reading characterized traditional approaches in social and personality psychology, and also the resulting division in labor in psychology departments in the twentieth century. The traditional approaches in personality psychology, Kihlstrom writes, ... 
... construed behavior as a function of person attributes such as traits, attitudes, emotions, motives, and values ... in such research, the effects of the environment are generally construed as "noise." The canonical method of traditional personality psychology thus exemplifies the Doctrine of Traits, which may be stated as follows: Social behavior varies as a function of internal behavioral dispositions that render it coherent, stable, consistent, and predictable. (2013, p. 793)

Traditional approaches in social psychology, on the other hand, ...

... construed behavior as a function of differences in the physical and (especially) social environment ... in such research the effects of individual differences in personality are generally construed as "noise." This view is captured by what might be called the Doctrine of Situationism: Social behavior varies as a function of features of the external environment, particularly the social situation, that elicit behavior directly, or that communicate social expectations, demands, and incentives. (p. 793)

The debate here is about how to best explain and predict behavior. Proponents of the Doctrine of Traits think that personality variables explain more of the variance in behavior, while proponents of the Doctrine of Situationism think that environmental variables do more of the explanatory work. It is worth flagging here that, when construed in this way, the person-situation debate affords a reading in terms of internalism and externalism, respectively. I will return to this point below.

Much psychological research in the twentieth century was conducted along these person-situation party lines, where the relationship between partisans was described as "benign collegial neglect" (Kihlstrom, 2013, p. 794). That changed, however, with the publication of Walter Mischel's (1968) Personality and Assessment, which was received at the time as a devastating critique of personality psychology. In an oft-quoted passage, Mischel claims:

With the possible exception of intelligence, highly generalized behavioral consistencies have not been demonstrated and the concept of personality traits as broad response predispositions is thus untenable ... The initial assumptions of trait-state theory were logical, inherently plausible, and also consistent with common sense and intuitive impressions about personality. Their real limitation turned out to be empirical-they simply have not been supported adequately. (pp. 146-147)

Another popular soundbite is that in the personality literature reviewed by Mischel, the correlation between scores on various personality measures and actual behavior was about $r=.3$, meaning that only $10 \%$ of the variance in behavior is explained by personality variables. Setting to the side methodological and interpretative qualms with Mischel's review, Personality and Assessment did turn out to be rather devastating to personality psychology at the time. Swann and Seyle (2005) show that after the publication of Personality and Assessment, there was "a marked decline in the number of research studies, graduate training programs, and dissertations devoted to personality psychology" (p. 156), and this lasted well into the 1970s.

Among others, work by David Funder and colleagues helped to reverse this trend. Most notably, Funder and Ozer (1983) showed that once the $t$ and $F$ statistics 
often reported in social psychological and situationist studies are converted to the $r$ statistic often reported in personality and individual difference studies, ...

... the effects on behavior of several of the most prominent Situational factors in social psychology seem to average slightly less than .40. Moreover, because in most social psychological experiments only two or three levels of the situational independent variable are studied, and because these levels usually are deliberately chosen to be quite different from each other, situational linear effects such as calculated here quite possibly overestimate the true state of affairs. (Funder \& Ozer, 1983, p. 110)

In other words, once apples are compared to apples, the predictive and explanatory power of the traditional social psychological and situational measures are not much different from personality and individual difference measures. Indeed, in a meta-analysis of more than 25,000 studies involving 8 million participants, Richard, Bond, and Stokes-Zoota (2003) find that the mean effect size for person and situation effects are .19 and .22, respectively (p. 337). It seems, then, that, situations are no better at explaining behavior than are persons.

Recall that all of the preceding discussion has been based on the assumption that the comma in Lewin's equation signified an additive, or independent relationship between persons and environments. As a matter of contingent historical fact, this is how social and personality psychology developed as disciplines, but it is not the only way to interpret the relationship between persons and environments. To cite just one of many possible contemporary examples, Mischel himself notes, in a 40-year retrospective on Personality and Assessment, that the most promising approaches in social and personality psychology ...

... bridge the classic partitioning most unnatural and destructive to the building of a cumulative science of the individual-the one that splits the person apart from the situation, treating each as an independent cause of behavior. At the time of the "person versus situation" debate, this splitting (amazingly) threatened to make personality the discipline that studies people apart from situations, and social psychology the unfriendly neighbor that studies situations apart from people. (2009, p. 289)

In other words, the Doctrines of Traits and Situationism, taken independently, constitute a false dichotomy. The takeaway is that you can ask any contemporary social or personality psychologist about the person/situation debate and they will likely tell you that it is over, and has been for some time.

\subsection{The extended cognition debate}

In the previous section I mentioned that the person-situation debate affords a reading on which the Doctrine of Traits might be roughly understood as a form of internalism and the Doctrine of Situationism might be roughly understood as a form of externalism. In this section, I will tell the other half of the story needed to cash out that claim.

It is worthwhile to begin by noting the arbitrariness of marking the genesis of extended cognition, as is standard practice in the literature, with the introduction 
of Inga and Otto. The extended cognition debate, like the person-situation debate, has a history with its roots in early twentieth century philosophy and psychology. Starting with Otto's notebook, then, risks ignoring the historical depth of the ideas and concepts in the debate. If only in passing here, it is helpful to note that the classical American pragmatists were saying things like the following, nearly a century before Otto was trying to find the MoMA. John Dewey, for instance, says:

Thinking, or knowledge getting, is far from being the armchair thing it is often supposed to be. The reason it is not an armchair thing is that it is not an event going on exclusively within the cortex ... Hands and feet, apparatus and appliances of all kinds are as much a part of it as changes within the brain. (Dewey, 1916/2004, p. 9)

And C.S. Peirce:

Modern philosophy has never been able to quite shake off the Cartesian idea of the mind, as something that "resides," - such is the term - in the pineal gland. Everybody laughs at this nowadays, and yet everybody continues to think of mind in this same general way, as something within this person or ... belonging to him and correlative to the real world. (Peirce, 1903/1998, p. 199)

Indeed, many scholars have noted that the pragmatist cannon is a fruitful but underutilized resource for extended cognition theorists (e.g., Chemero, 2011; Gallagher, 2014; Madzia, 2013; Rockwell, 2005; Skorburg, 2013; Vaesen, 2014). I won't belabor that point here, but it should hardly be surprising that the same school of thinkers who brought the concept of symbolic interactionism to sociology and psychology (e.g., Mead, 1934/1962) would play a role in the development of the theories of that have come to characterize social psychology and its parallels with extended cognition.

While my story begins with the classical pragmatists, like all other accounts of the extended mind and cognition, it also runs through Clark and Chalmers's (1998) classic thought experiment, which readers here are no doubt familiar with by now. ${ }^{1}$ But before getting into the thick of the contemporary debates, it is worthwhile to mark a distinction at the outset, as the failure to do so has created much confusion in the literature. The distinction is between the hypotheses of the extended mind (HEM) and of extended cognition (HEC). Pöyhönen (2014), Bernecker (2014), and others have noted that the latter is "a claim about cognitive processing," where the former "concerns the location of human mental states," and that crucially, these distinct hypotheses "apply to different domains, address largely different issues, and depend on different sources of evidence" (Pöyhönen, 2014 , p. 737). One implication of this distinction is that claims concerning HEC are evaluated with respect to the explanatory standards of the sciences of the mind, while claims concerning HEM are evaluated with respect to our folk psychological intuitions about mentality. Because this paper is ultimately aimed at introducing a new body of empirical work to philosophical debates, my positive arguments (sections 2 and 3) are primarily pitched at the domain of HEC. But because the present section is largely historical in nature, I won't fret about other authors' equivocation on HEM/HEC. 
In the story I want to tell about the development of extended cognition, the relevant trajectory is structured by claims about coupled systems:

In these cases [of extended cognition], the human organism is linked with an external entity in a two-way interaction, creating a coupled system that can be seen as a cognitive system in its own right. All the components in the system play an active causal role, and they jointly govern behaviour in the same sort of way that cognition usually does. If we remove the external component the system's behavioural competence will drop, just as it would if we removed part of its brain. Our thesis is that this sort of coupled process counts equally well as a cognitive process, whether or not it is wholly in the head. (Clark \& Chalmers, 1998, pp. 8-9)

The debate about extended cognition became a debate in large part due to Adams and Aizawa $(2008,2009,2010)$, and in particular, their formulation of the coupling-constitution fallacy, which has also long since been familiar to readers. ${ }^{2}$ The charge has nonetheless been a persistent thorn in the side of extended mind and cognition theorists, and it leads to a more general worry: without principled criteria for distinguishing mere coupling from full-blown constitution with respect to cognitive processes or mental states, we might be led to what Rowlands describes as the problem of cognitive bloat:

Once we permit such processes, where do we stop? Our conception of the cognitive will become too permissive, and we will be forced to admit into the category of the cognitive all sort sorts of structures and processes that clearly are not cognitive. (2013, p. 86).

What's important for my purposes is that the coupling-constitution fallacy and cognitive bloat worry focus the debate on the precise nature of the relationship between the internal processes of the cognitive agent and those external entities to which the agent is coupled. Heersmink (2015), drawing on previous attempts (e.g., Clark \& Chalmers, 1998; Sterelny, 2010; Sutton, Harris, Keil, \& Barnier, 2010; Wilson \& Clark, 2009), helpfully proposes an 8-dimensional taxonomy to map the conceptual space between mere coupling and full-blown constitution. The dimensions are:

- information flow

- reliability

- durability

- trust

- procedural transparency

- informational transparency

- individualization

- transformation

The idea is that the more highly a coupled system scores along these dimensions, the more tightly integrated the system is, and the stronger is the argument for extension. To put it slightly differently, and to foreshadow a bit, high scores along these dimensions would indicate that the pathways of influence between the 
components of a coupled system are roughly symmetrical, balanced, and reciprocal, where lower scores would indicate asymmetric, imbalanced, and non-reciprocal influence between components. I will return to this point in the next section. In less fine-grained but more familiar terms, the space between coupling and constitution has also been described in terms of mere coupling (e.g., Adams \& Aizawa, 2010), embedding (e.g., Rupert, 2004), scaffolding (e.g., Sterelny, 2010), and, of course, extending (e.g., Clark, 2008).

However we cut the pie, most seem to agree that in order to make an argument for cognitive extension, principled criteria are needed to distinguish cases of mere coupling from full-blown constitution. ${ }^{3}$ On Heersmink's (2015) model, for example, extension looks like ...

... systems with a high-bandwidth, reciprocal information flow, where the artifact is reliably available, the relation between agent and artifact is durable, the information it provides is trustworthy, the artifact is procedurally and informationally transparent, it is individualized or possibly even entrenched, and its representational systems has transformed the brain of its user. (p. 595)

On my telling, this passage and others like it represent the most mature and plausible formulations of the nature of extended cognition. To be sure, this sets the bar for extension rather high, and it seems likely that blocking the coupling-constitution and cognitive bloat objections in this way may come at the cost of conceding that Otto's notebook, for example, is closer to coupling than constitution. That question needn't be settled here, however, as my purpose is only to trace the trajectory of the coupled systems aspect of the extended cognition debate. So to sum up, we can tell a story about extended cognition which has its roots in early 20th century American philosophy and psychology, develops more fully as a theory about coupled systems and then reaches a mature formulation in the context of strict, specifiable criteria for extension.

\section{Connections}

With both narratives now in place, my aim in this second part of the paper is to make explicit what I take to be the most important connections between them (section 2.1). In order to strengthen these connections, I identify and respond to two possible objections to my proposal (section 2.2). I will then go on in section 3 to use these connections as the basis for supporting certain formulations of extended cognition over others (section 3.1) and identifying promising new directions for extended cognition research (section 3.2).

\subsection{Agent-environment interactions}

Here's a first pass at the similarities I will use to make my case: we can tell a coherent narrative about the development of the person-situation debate and the extended cognition debate which begins in both cases with a dichotomy which 
is eventually eschewed in favor of an interactionist conclusion with a gradient of positions in between. The thread that ties these narratives together is the common interest in the nature of agents, environments, and their interactions.

In the history of the person-situation debate, the dichotomy is pretty straightforward: adherents of the Doctrine of Traits thought individual difference measures-personality traits that inhered in the agent-were the best way to predict and explain behavior. Adherents of the Doctrine of Situationism thought the same about environmental and situational influences external to the agent. While it is doubtful than few, if any, psychologists were actually staunch adherents of one doctrine at the total expense of the other, Kihlstrom (2013) does make a convincing case on historical grounds that these doctrines did structure much early research in the development of what we now know as social and personality psychology.

In the extended mind and cognition debates, the dichotomy is less stark but still apparent. Clark and Chalmers never claimed that all cognitive processes or mental states were extended, nor did internalist critics ever claim that features external to the brain had no influence on cognition. But still, as Ross and Ladyman (2010) point out, Adams and Aizawa's coupling-constitution fallacy isn't just pitched as a criticism of Clark and Chalmers's externalism-it is also a defense of internalism (p. 155). Much of what is at stake in these debates is the question of what sorts of structures and processes ought to figure into cognitive scientific theories, predictions, and explanations. In this sense, much of the early debate surrounding the extended mind and cognition did have a rather internalist versus externalist flavor.

As the debate evolved, however, a number of nuanced positions were staked out between the poles of internalism and externalism about the mind and cognition. Rob Rupert's formulation of the hypothesis of embedded cognition ${ }^{4}$ and Kim Sterelny's formulation of the hypothesis of scaffolded cognition are exemplars here. The latter is more germane for present purposes: "the scaffolded mind hypothesis proposes that human cognitive capacities both depend on and have been transformed by environmental resources. Often these resources have been preserved, built or modified precisely because they enhance cognitive capacity" (Sterelny, 2010, p. 472). In the framework of traditional internalism or Rupertstyle embedding, the environment is exogenously determined. Cognitive agents depend on and learn to exploit external features of their environment, but they may not modify those environments in important or systematic ways. Sterelnystyle scaffolding, in contrast, construes the external environment as at least sometimes endogenously determined: it is a partially built environment, and it is often engineered to enhance or scaffold our cognitive capacities. This view cuts across a simple distinction between internal and external resources in the sense that an agent can actively sculpt the environment to determine how and what sorts of external entities she can interact with and come to depend on. The reliable presence of these external entities in turn shapes the internal capacities of the agent in new ways, which changes the sorts of external entities she interacts with, and so on. 
There are a number of analogs in social and personality psychology which similarly served to undermine a strict dichotomy between the internalism of personality traits and the externalism of situational influences. Ickes, Snyder, and Garcia (1997) review the vast literature in personality psychology which has studied the ways in which the active selection of situations can be understood as a function of personality. They come to the following conclusion.

That people actively gravitate toward some types of situations and deliberately avoid others, and that their choices of situations are reflections of features of their personal identities (including such dispositions as attitudes, traits, and conceptions of self), may constitute major sources of the regularities, stabilities, and consistencies in behavior that are typically regarded as defining characteristics of personality (p. 186).

A significant component of personality, in other words, is the disposition to seek out certain kinds of situations (usually situations that are not discrepant with one's self-concept) and avoid others (usually situations that are discrepant with one's self concept). And selecting situations in this way solidifies certain aspects of personality, which in turn leads to seeking out and avoiding certain kinds of situations, and so on. In much the same way Sterelny talks about cognitive scaffolding, a robust literature in personality psychology suggests that people can and do actively sculpt the situations they will encounter, and in so doing, generate the sorts of consistent behavioral, cognitive, and affective dispositions which characterize personality.

The concepts of cognitive scaffolding and situation selection both highlight the inadequacy of strict distinctions between agents and environments. As I have hinted above, once these inadequacies are noted, a form of interactionism follows as the most plausible solution. In the case of the person-situation debate, to cite one of many possible examples, this is made quite explicit:

The persistence of this [person-situation] debate into the 21st century is something of a mystery. Since at least the 1930s, deep thinkers as diverse as Allport (1937) and Lewin (1951) have argued that invidious comparisons miss the point because behavior is a function of an interaction between the person and the situation. By the 1980s this recognition had deteriorated into a truism. Nowadays, everybody is an interactionist. (Funder, 2006, p. 22)

In the philosophy of mind, the language might not be as explicit, nor the conclusion as widespread. But Palermos (2014), borrowing terminology from Dynamical Systems Theory, makes a strong case for adopting necessary and sufficient conditions for (cognitive) extension which have an unmistakable interactionist ring.

In cases where two nonautonomous systems mutually interact on the basis of feedback loops, there is an ongoing causal amalgam between the two units that disallows their decomposition into two separate systems on the basis of distinct inputs and outputs ... The reason is that the way each component is affected is not exogenous to the component itself, and so cannot be properly thought of as its input. Likewise, the way each component affects the other is directly and synchronically related to the component to be affected and so cannot be properly conceptualized as output of the affecting component ... We can call this the "ongoing feedback loops" argument for the (ontological) 
postulation of coupled systems ... In other words, ongoing mutual interdependence on the basis of feedback loops is the criterion by which we can judge whether two seemingly distinct systems constitute an overall system, consisting of both of them. (pp. 33-34)

This notion of mutual interdependence on the basis of ongoing feedback loops is the crux of my account of interactionism. I take Palermos to be asserting that (among other things) component $X$ must be able to affect component $Y$ in roughly the same way as component $Y$ can affect component $X$ in order for $X$ and $Y$ to constitute an extended coupled system. And I take it that Heersmink (2015) has something similar in mind, especially with respect to the dimensions of reciprocal information flow and mutual transformation noted above, both of which seem to require the kind of bi-directionality emphasized by Palermos. Huebner's (2016, p. 52) distinction between exploitation and collaboration is also in this same spirit. What ties all of these proposals together, I submit, is an emphasis on inter-action in a strict sense, characterized by symmetry, balance, and reciprocity of the pathways of influence between components of the coupled system. ${ }^{5}$ This shared sense of interactionism underwrites what I take to be the most plausible formulations of extended cognition.

By highlighting the similarities in the evolution of the person-situation and extended cognition debates, from their beginnings in terms of a dichotomy (Doctrine of Traits versus Doctrine of Situationism and Internalism versus Externalism), through the development of a gradient in between (situation selection as personality trait and cognitive scaffolding), to a proposed resolution in terms of interactionism ("nowadays, everyone is an interactionist" and the ongoing feedback loops criterion, etc.), I hope to have made the case that there are indeed important and instructive parallels between the development of social and personality psychology and the extended cognition research program. In what follows, I'll advance some positive arguments that I think follow from this. But first, I'll consider two objections to the connection I have drawn here.

\subsection{Objections}

The first and most formidable objection is that an old debate about the explanation and prediction of behavior is orthogonal to a contemporary debate about the nature of cognitive processes. Relatedly, one might also object that the sort of internalism and externalism represented by the Doctrines of Traits and Situationism is disanalogous to the debates about extended cognition-that the relation of the person to the situation is different in kind from the relationship of, say, Otto to his notebook. If these objections are on the right track, then the resolution of the person-situation debate wouldn't tell us anything about the extended cognition debate. I'll try to show that this isn't the case.

Regarding the first objection that the two debates are orthogonal, it should be pointed out that a number of philosophers have already begun to make a 
connection between social and personality psychology and the extended mind and cognition debates. The connection has largely been drawn in the context of the so-called situationist challenges to virtue theory. ${ }^{6}$ Doris, one the pioneers of the situationist challenge to virtue ethics, briefly addresses the extended cognition debate in his (2015) book which seeks to sort out the implications of a wide range of psychological research for philosophical theories of agency, reflection, and responsibility. In discussing the possibility of transactive memory in long-term romantic partners (more on this below), Doris refers to the extended cognition debate to stake out his position. He ultimately thinks that transactive memory can be explained in the framework of Rupert-style embedding rather than Clark and Chalmers-style extension (pp. 190-192). But the use of concepts from the extended cognition debate in interpreting social psychological research is, I think, indicative of an important connection between the two.

More substantively, Alfano and Skorburg (2016) explicitly argue that extended mind-style arguments could offer a response to the situationist challenges to moral and intellectual character:

If those mental states are sometimes extended, perhaps the dispositions to have them are too. Presumably, the dispositions don't extend in every case, just as the states don't extend in every case. Perhaps some people are honest all on their own. Perhaps some people are intelligent all on their own. But if our suggestion is on the right track, in some cases, a person is honest because (among other things) she is suitably integrated with props, tools, or other people outwith her brain and body. Likewise, if our suggestion is on the right track, in some cases, a person is intelligent because (among other things) he is suitably integrated with props, tools, or other people outwith his brain and body. (p. 2)

Howell (2016) makes a similar argument, drawing on situationist social psychology and the extended mind debate to make an argument against what he calls traditional "skindividualism" and in favor of something like extended virtues. Without venturing further into the weeds of the situationist challenges to virtue theory, the fact that these thinkers have identified a range of resources in the extended mind and cognition literatures to bring to bear on aspects of the person-situation debate, and vice versa, tells against the objection that the two debates are orthogonal. Connections have already been made between them and in this paper, I'm trying to draw these connections out more explicitly and in new directions.

Regarding the second objection-that persons don't extend to situations in the same way that agents extend to their artifacts-I concede that this is, strictly speaking, true. But I am arguing by analogy here and no analogy is perfect. All I need to show is that the argumentative moves in these debates are similar enough that one might profitably inform the other. To that end, I would point out that Lewin himself does claim that the situation includes the person and is not separate from it. This is not obviously a constitution claim, but it is not so foreign to claims made by friends of extended cognition, either: "the psychological environment has 
to be regarded functionally as a part of one interdependent field, the life space, the other part of which is the person" (Lewin, 1939/1951, p. 140, quoted in Kihlstrom, 2013, p. 794). Kihlstrom goes on to elucidate Lewin's view as being that, "persons are part of the situation to which they respond-or, put another way, that persons and situations together constitute a unified field in which behavior takes place" (pp. 795-796, emphasis in original).

For Lewin, at the level of behavior, there is no strict distinction between persons and situations. On this view, it then makes sense to say-recalling Clark-that behavior is the result of an inextricable tangle of feedback and feedforward loops, promiscuously crisscrossing the boundaries of persons and situations. Seen in this light, Clark and Chalmers's claim that "there is nothing sacred about skull and skin" (1998, p. 14) looks like old Lewinian field theory wine in new functionalist bottles. In (roughly) the same way that internal personality traits and external situational influences can conspire to produce behavior, so too can internal neural resources and external scaffolds conspire to produce cognition.

The interchangeability of the argument forms from the person-situation and extended cognition debates suggest that, far from being disanalogous, the two can actually inform one another. Not only can the terms from the debates about extended cognition help to clarify the person-situation debate (e.g., Doctrine of Traits as internalism, Doctrine of Situationism as externalism, situation selection as scaffolding, etc.), but the terms from the resolution of the person-situation debate (e.g., "nowadays, everyone is an interactionist"), can-or so I will argue below-help to resolve debates about extended cognition.

Summing up, my claim here is not that there is perfect correspondence between the person-situation and extended cognition debates. There isn't. What I hope to show, however, is that while old debates about the prediction and explanation of behavior may seem unrelated to contemporary debates about the nature of cognitive processes, there are in fact important and illustrative similarities between them, and a number of thinkers have already begun to connect these dots. Thus, the need for a detailed and explicit account of the connections between themprecisely what I aimed to give in this section-is all the more apparent. And given these connections, an account of the entailments and repercussions is also needed. That is my task for the balance of the paper.

\section{Implications and new directions}

If my narratives in section 1 were coherent and if my case for the connections between them in section 2 holds, I take it that there are important and instructive parallels between some aspects of social and personality psychology and some aspects of the extended cognition debate. In this final section, I examine what follows from this connection. I will argue that if my comparison holds, then interactionist conceptions of extended cognition ought to be favored over less interactionist alternatives (section 3.2). I will then argue, somewhat independently, that 
contemporary research in social and personality psychology provides the most plausible direction for the future of extended cognition research (section 3.2).

\subsection{Implications}

Sutton (2010) identifies the first wave of extended mind arguments as committed to the parity principle, where the second wave is characterized by a commitment to the complementarity principle. ${ }^{7}$ It is an open question what constitutes the third wave, but Shaun Gallagher's (2013) "Socially Extended Mind" seems a good candidate, as it pushes extended mind and cognition arguments in a new direction and has generated a number of responses in doing so. ${ }^{8}$ I agree with the letter of Gallagher's proposal: the social domain is the new frontier for extended cognition. I disagree, however, with the operationalization of the socially extended mind in terms of mental institutions (e.g., Gallagher \& Cristafi, 2009). Gallagher's proposal is that mental institutions "like legal systems, research practices, and cultural institutions" (2013, p. 6) offer the best prospects for the socially extended mind.

The first positive argument I want to make is that in roughly the same way that the person-situation debate is resolved in terms of interactionism, so too, ought the extended cognition debate be resolved in terms of interactionism. ${ }^{9}$ More specifically, we ought to give pride of place to proposals like Palermos's (2014) ongoing feedback loops criterion, or Heersmink's (2015) dimensions of reciprocal information flow and mutual transformation, which emphasize the symmetric, balanced, and reciprocal pathways of influence between components of coupled systems. On these interactionist views, a number of problems arise with Gallagher's formulation of the socially extended mind. First, the distinctions (and hence, the standards of evaluation) are blurred between HEM and HEC. More substantively, though, none of the examples Gallagher invokes meet the interactionist standards of symmetry, balance, and reciprocity. It is hard to see, for example, how a paralegal assistant could exert the same kind of influence on decades of legal precedent as the precedents exert on them. That is, the pathways of influence between the paralegal and the law are probably best described as asymmetric. Perhaps we could charitably grant that the relationship is symmetric and imbalanced, but in any case, we are nowhere near reciprocity-one of the hallmarks of interactionism. And things don't look any better for Gallagher's even more nebulous examples of research practices and cultural institutions.

As I mentioned in section 2.2, adopting something like the ongoing feedback loops criterion comes at the cost of relegating some putative cases of extended cognition to the framework of embedding. I agree, then, with Huebner's (2013) assessment that Gallagher's formulation of the socially extended mind is more accurately rendered as the socially embedded mind in just this way. This is not to say that the socially extended mind isn't important in its own right, but rather, that it does not offer a plausible path forward for extended (as opposed to embedded or scaffolded) cognition research. Insofar as something like the interactionism 
represented by the ongoing feedback loops criterion sets the bar, then Gallagher's socially extended mind will fall short.

The next question to ask, of course, is whether the criteria on offer are too restrictive. What does get over the bar? Palermos (2014) makes a case that tactile visual substitution systems (TVSS) are strong candidates for extension. ${ }^{10}$ While TVSS probably does pass muster, I think it is probably closer to the exception than the rule, and this brings me to the next phase of my positive argument. If we take seriously the interactionist lessons from the person-situation debate, then the standard agent-artifact paradigm (e.g., Otto and his notebook or Dave and his iPhone), operative in nearly all accounts of the extended mind and cognition, may be called into question. My claim - and here I possibly part ways with Palermos-is that once we take seriously the sort of interactionism I've described, many agent-artifact systems will not reliably exhibit the right kind of bi-directional, reciprocal feedback necessary for extension, at least not as reliably as many agent-agent systems will. ${ }^{11}$ The most important connection, then, between the extended cognition debate and the person-situation debate is the striking similarity between the interactionism exemplified in proposals like the ongoing feedback loops criterion and some models of social interaction from the history of social and personality psychology. Consider Darley and Fazio's (1980) model of the social interaction sequence:

(1) Either because of past observations of the other or because of the categories into which he or she has encoded the other, a perceiver develops a set of expectancies about a target person. (2) The perceiver then acts toward the target person in a way that is in accord with his or her expectations of the target person. (3) Next, the target interprets the meaning of the perceiver's action. (4) Based on the interpretation, the target responds to the perceiver's action, and (5) the perceiver interprets the target's action. At this point, the perceiver again acts toward the target person and so can be regarded as reentering the interaction sequence loop at Step 2 ... (6) After acting toward the perceiver, the target person interprets the meaning of his or her own action. (p. 868 $)^{12}$

Kihlstrom (2013) describes this process-more accurately, I think-as a cycle of social interaction rather than a sequence (p. 787). Similar accounts can be found in Cantor and Kihlstrom (1987) and Jones (1986). It is important to note that these models are all elaborated in the context of research on expectancy confirmation effects, more colloquially known as self-fulfilling prophecies. My claim is that the interactions modeled in this research program will reliably exemplify the sort of feedback described by Palermos (2014), Heersmink (2015), Huebner (2016), and others.

In narrative form, the idea is this: I think of you as an honest person because, among other things, I've seen you behave honestly in the past. As we're walking down the street today, a stranger in front of us drops a $\$ 100$ bill from her pocket. I might (consciously or unconsciously) signal my expectation of your honesty-a quick glance at you, then at the stranger in front of us, then back at you. You might then interpret my glance as my expecting you to flag down the stranger 
and return the bill. And you might do just that. If you do, my expectations of you are confirmed and even strengthened: "You really are a genuinely honest person," I might say. In turn, you might think to yourself, "It's true, I really am an honest person." The next time we're in a similar situation, my expectations will be even stronger, and perhaps you'll be even more likely to do something similarly honest. Perhaps you'll even be more likely to do so when I'm not there signaling my expectations to you. ${ }^{13}$

The ping-ponging between my expectations and subsequent signaling, your interpretation of them and subsequent behavior, my interpretation of your behavior and subsequent updating of my expectations, and so on, is paradigmatic of Palermos's idea of "ongoing mutual interdependence on the basis of feedback loops (2014, pp. 33-34)" and Heersmink's requirement of reciprocal information flow. This kind of bi-directional, mutual interdependence is at the core of many kinds of social interactions, and for this reason, offers the most plausible paradigm for thinking about extension in terms of interactionism. Put another way, other agents are more likely than (many) artifacts to exhibit the required kind of time sensitive, reliable, and reciprocal influence.

\subsection{New directions}

The second point that follows from the connection I've drawn is related to the first, but can, I think, ultimately be decoupled from it. This second claim is that recent research in social and personality psychology-especially research on close relationships-offers a promising route for developing the next wave(s) of the extended mind and cognition research programs. If my argument for interactionism in section 3.1 went through, then this point should follow very naturally. If agent-agent systems are a better way to think about extended cognition-style arguments in light of Palermos (2014), Heersmink (2015), and others, then the disciplines that study agent-agent couplings would seem well-equipped for the task. In this section, I'll try to show how some research programs in social and personality psychology do just this. But even if the argument from the previous section falls short, my claims in this section about the potentially shared resources between social and personality psychology and extended cognition need not fall with it.

I want to begin by noting that the proposal I'm making is already, in a sense, underway with respect to the recent interest in Transactive Memory Systems (TMS) among friends of extended cognition (e.g., Harris, Keil, Sutton, Barnier, \& McIlwain, 2011; Huebner, 2016; Kirchhoff, 2015; Sutton et al., 2010; Theiner, 2013; Tollefsen, Dale, \& Paxton, 2013).

The concept of a Transactive Memory System is due to a series of papers by Dan Wegner and colleagues (e.g., Wegner, 1986, 1995; Wegner, Giuliano, \& Hertel, 1985). ${ }^{14}$ Perhaps the most well-known is Wegner, Erber, and Raymond's (1991) "Transactive Memory in Close Relationships" which, it should be noted, was 
published in the Journal of Personality and Social Psychology. Therein, TMS is described as follows:

People in close relationships know many things about each other's memories ... Such knowledge of one another's memory areas takes time and practice to develop, but the result is that close couples have an implicit structure for carrying out the pair's memory tasks. With this structure in place, couples in close relationships have a transactive memory that is greater than either of their individual memories. Transactive memory is a shared system for encoding, storing, and retrieving information. (p. 923)

This is low-hanging fruit for the extended cognition theorist. Here we have a claim (with empirical evidence, to boot) that the cognitive processes of remembering, recollecting, cueing, and so on can be realized between two individuals in a romantic relationship. The findings of the paper are indeed compelling. Romantic partners without an assigned structure (e.g., one partner is told remember items from categories 1 and 2, the other partner, 3 and 4) exhibited significantly more agreement about which partner was more expert in a given category $(M=5.52)$ than randomly assigned impromptu partners $(M=4.04)$ and romantic partners recalled significantly more items $(M=31.4)$ than did impromptu partners $(M=27.64)$.

I don't mean to imply that this is a knockdown argument for extended cognition, but the "communication and updating of information each has about the areas of the other's knowledge," and its outcome that "each partner cultivates the other as an external memory aid" (p. 924) smacks of the kind of interactionism I've been pushing in this paper. Perhaps the most surprising result from these studies is that that when structures were assigned to the partners, not only did the effects just described disappear, they actually flipped: romantic partners with an assigned structure recalled significantly fewer items $(M=23.75)$ than did impromptu partners $(M=30.14)$. In these cases, there seems to be something quite important about each partner cultivating and being cultivated by the other, that is, knowing what the other knows and knowing that they know that you know it. It is no surprise, I want to say, that extended cognition proponents can get mileage out of these kinds of studies: TMS seems, on the face of it, to meet even the strictest standards of interactionism. ${ }^{15}$

At the very least, TMS seems to provide a better lodestone for extended cognition theories than Otto's notebook. Indeed, construing TMS as a shared system for encoding, storing, and retrieving information provides an empirically tractable (and thus, HEC friendly) framework which avoids many of the persistent objections to HEM. ${ }^{16}$ More ambitiously though, this body of research offers a springboard into research in social and personality psychology for the next wave of the extended mind and cognition. One upshot of the recent interest in TMS, I hope, will be an increased awareness of the robust literature in personality psychology on romantic partnerships beyond TMS-type cases. This seems to me the most promising arena for interactionist, agent-agent conceptions of extended cognition. In the spirit of advancing the extended cognition research programs in new directions, however, theorists need not be confined to classic cognitive 
processes like memory and problem solving, though there is plenty to consider here too. An exciting but underexplored area involves the process of attribution in close relationships. For example, a study by Srivastava, McGonigal, Richards, Butler, and Gross (2006) shows how trait-optimism-the disposition to expect positive outcomes-makes positive outcomes like satisfaction, feeling supported, and resolving conflicts more likely in romantic relationships. Relatedly, there is a large body of literature about the role of positive illusions in relationships (e.g., Martz et al., 1998; Murray \& Holmes, 1997; Murray, Holmes, \& Griffin, 1996a, $1996 b)$ which is very much in-line with the self-fulfilling prophecy paradigm cited above as an exemplar of interactionism. ${ }^{17}$

These are but a few examples from a much larger body of work which offers one of the most promising future directions for the extended cognition research program. This much should still hold true, even if the arguments from section 2 and section 3.1 fail. But if the arguments up to this point are on the right track, social and personality psychology in general-and research on romantic partnerships in particular-is well-positioned to contribute to a robustly interactionist theory of extended cognition. Setting all of that argumentation to one side, I also straightforwardly agree with Doris that "there's something sweet about saying that the members of a devoted couple are literally part of one another" (2015, pp. 191-192).

\section{Conclusion}

The literature surrounding the situationist challenges to virtue theory played a large role in opening the doors for philosophers to engage with social and personality psychologists. As I hinted at in section 2.2 , the extended cognition debate has also begun to enter this fray. If this paper has succeeded in its aims, then it will have opened similar doors, and perhaps even nudged some to go through.

To sum up and conclude: I tried to highlight instructive parallels between the person-situation debate in social and personality psychology and the extended cognition debate in the philosophy of mind. I argued that the resolution of the former in terms of interactionism lends support for the analogously interactionist formulations of extended cognition proposed by Palermos (2014), Heersmink (2015), and others. I then argued that in this interactionist framework, the most plausible cases of extension might not be agent-artifact couplings like Otto and his notebook or Dave and his iPhone, but rather, agent-agent couplings such as transactive memory systems in romantic partnerships. If this is right, then social and personality psychology-the discipline(s) that developed from the person-situation debate-represent a whole new range of empirical considerations for extended mind and cognition theorists.

These new considerations, I suspect, may take us away from a sometimes overly narrow focus on extended cognitive processes, and bring us closer to an often overlooked aspect of Clark and Chalmers's original vision: "far better to take the 
broader view, and see agents themselves as spread into the world" (1998, p. 18, emphasis added). ${ }^{18}$

\section{Notes}

1. But if not, here's a brief recap: Inga's biological memory is perfectly intact. She hears about an exhibit she'd like to see at the Museum of Modern Art. She recalls that the MoMA is on 53rd St., and so walks to 53rd and goes to see the art exhibit. Otto suffers from Alzheimer's, and so he carries a notebook with him everywhere he goes, writing down those things that folks like Inga would normally commit to biological memory. Otto, too, hears about the art exhibit and also wants to see it. So Otto consults his notebook and finds that the MoMA is on 53rd, and then walks to 53rd and goes to see the art exhibit. "In relevant respects," according to Clark and Chalmers, "the cases are entirely analogous: the notebook plays for Otto the same role that memory plays for Inga. The information in the notebook functions just like the information constituting an ordinary non-occurrent belief; it just happens that this information lies beyond the skin" (1998, pp. 12-13).

2. But if not, here's their formulation: "When Clark makes an object cognitive when it is connected to a cognitive agent, he is committing an instance of a couplingconstitution fallacy. This is the most common mistake that extended mind theorists make. The fallacious pattern is to draw attention to cases, real or imagined, in which some object or process is coupled in some fashion to some cognitive agent. From this, one slides to the conclusion that the object or process constitutes part of the agent's cognitive apparatus or cognitive processing ... Yet coupling relations are distinct from constitutive relations, and the fact that object or process $\mathrm{X}$ is coupled to object or process $\mathrm{Y}$ does not entail that $\mathrm{X}$ is part of $\mathrm{Y}^{\prime \prime}$ (Adams \& Aizawa, 2010, pp. 67-68).

3. However, Hurley (2010) and Ross and Ladyman (2010) argue (in different ways) that the distinction between coupling and constitution is a specious one.

4. The hypothesis is that "cognitive processes depend very heavily, in hitherto unexpected ways, on organismically external props and devices and on the structure of the environment in which cognition takes place" (Rupert, 2004, p. 393). Rupert concedes that external entities might be more important for cognitive scientific explanations than we would have thought-cognition might depend on them in interesting ways. Rupert denies, however that these props, devices, and structures are constitutive of cognitive processes. If the framework of embedding can account for the same range of cases as extension without the dubious inference from coupling to causation, the argument goes, then ceteris paribus we should endorse the hypothesis of embedded cognition over the hypothesis of extended cognition by "the methodological principle of conservatism" (p. 395).

5. It would take us too far afield here to exhaustively map the logical space of these dimensions, but here's a start: to recall a terrible example from Adams and Aizawa (2010, p. 67) the mathematician-and-pencil coupled system exhibits asymmetry because the pencil could never influence the mathematician to the degree that the mathematician could influence the pencil. In this sense, all asymmetric coupled systems also exhibit imbalance in the pathways of influence between components and are therefore also not reciprocal. An example of a symmetric but imbalanced coupled system might be illustrated by something like Twitter trends. In principle, all Twitter users exert some influence on what is trending, and so the pathways of influence are (or are at least potentially) symmetric. But what Katy Perry tweets (with 
some 91 million followers as of this writing) has significantly more influence on Twitter trends than what I tweet (with my few dozen followers). Thus, there is an imbalance in the pathways of influence between components, and so no reciprocity. Lastly, symmetric, balanced, and therefore, reciprocal coupled systems are perhaps realized by the Tactile Visual Substitution Systems described by Palermos (2014, see note 11 below), but, as I will argue below, are more reliably realized by agent-agent coupled systems, such as long-term romantic partners. At any rate, these distinctions are simply meant to help clarify the notion of interaction on offer by synthesizing trends in recent scholarship. Future research should assess the degree to which they square with more entrenched distinctions in the literature (e.g., between embedding, scaffolding, etc.). Thanks to Mark Alfano for helping to develop these criteria.

6. In a sentence: the evidence from situationist social psychology, such as Darley and Latane's (1968) bystander studies, Darley and Batson's (1973) Good Samaritan studies, and Milgram's (1974) obedience studies, challenges the existence of the stable, consistent character traits countenanced by (neo)Aristotlean virtue ethics. See Doris (2002) and Alfano (2012) for detailed, book length treatments.

7. Here's Sutton's gloss on the Parity Principle: "first-wave EM [extended mind] is based on the parity principle: cognitive states and processes extend beyond the brain and into the (external) world when the relevant parts of the world function in the same way as do unquestionably cognitive processes in the head" (2010, p. 193). And the Complementarity Principle: "second-wave EM is based on a complementarity principle: in extended cognitive systems, external states and processes need not mimic or replicate the formats, dynamics, or functions of inner states and processes. Rather, different components of the overall (enduring or temporary) system can play quite different roles and have different properties while coupling in collective and complementary contributions to flexible thinking and acting" (p. 194).

8. The journal Cognitive Systems Research dedicated a special edition (Nos. 25-26) to Gallagher's formulation of the socially extended mind.

9. What I am proposing is close in spirit to Menary's (2007) notion of cognitive integration, but Menary's account lacks the sort of specific, detailed criteria offered by Heersmink (2015) or Palermos (2014).

10. Here's Palermos's take: "the mutual interaction between the agent and his tactile visual substitution system gives rise to new systemic properties (such as the new quasi-visual experiences produced, or new possibilities for interaction with the environment) that do not belong to any of the subsystems alone, but to the overall coupled system, ATVSS [Agent-Tactile Visual Substitution System] ... the postulation of coupled systems is necessary with respect to the explanation of certain systemic properties, which we would otherwise be at a loss how to account for" (p. 32).

11. To be perfectly clear, I think that many agent-artifact couplings do, in fact, make the cut now, and given the advance of interactive computational technologies, it is highly likely that many more will in the near future. My claim is simply that the dynamics of social interactions that exhibit the relevant characteristics (e.g., reciprocity) are more widespread and reliably realized. After all, TVSS and related technologies are often prohibitively expensive and not widely available. By comparison, the expectancy effects I discuss below are ubiquitous, especially in the context of friendships, romantic partnerships, and other close relationships. I don't think this claim contradicts the spirit of the proposals of Palermos, Heersmink, or Huebner. Rather, it should be seen as expanding their reach by showing how cognition can be extended not only by props and tools, but also by other people. 
12. It's worth noting here that Darley and Fazio identify symbolic interactionism as the precursor to this model, and it is for this reason I think it is important to consider the role of the classical pragmatists like Dewey and Mead in the development of the extended mind and cognition. For more on the relationship between the "Chicago School" pragmatists and the extended mind, see Madzia (2013).

13. This vignette is just a quick adaptation of Alfano's (2012) notion of a factitious virtue.

14. For helpful reviews of TMS research, see Lewis and Herndon (2011) and Ren and Argote (2011).

15. But see Huebner (2016) for a nuanced discussion of which parts of TMS fit into which parts of the extended mind and cognition debate.

16. Thanks to an anonymous referee for pointing out this additional upshot of my argument.

17. Of particular interest in this body of research on romantic partnership is the "Actor Partner Interdependence Model” (APIM) (e.g., Cook \& Kenny, 2005; Kashy \& Kenny, 1999; Kenny, 1996). This model is employed in research on dyads (such as married couples or parent-child relationships) to conceptually and statistically account for both effects of individual actors and effects of the dyad as a single unit. The notion of interdependence in these models provides one plausible route for operationalizing the concept of interaction discussed in this paper.

18. Many thanks are due to two anonymous referees whose careful and critical feedback improved my arguments. I am also indebted to Mark Alfano, Nicolae Morar, and Mark Johnson for helpful conversations while developing this paper.

\section{Disclosure statement}

No potential conflict of interest was reported by the author.

\section{References}

Adams, F., \& Aizawa, K. (2008). The bounds of cognition. New York, NY: Blackwell.

Adams, F., \& Aizawa, K. (2009). Why the mind is still in the head. In M. Aydede \& P. Robbins

(Eds.), The Cambridge handbook of situated cognition (pp. 78-95). Cambridge: Cambridge University Press.

Adams, F., \& Aizawa, K. (2010). Defending the bounds of cognition. In R. Menary (Ed.), The extended mind (pp. 67-80). Cambridge, MA: MIT Press.

Alfano, M. (2012). Character as moral fiction. Cambridge: Cambridge University Press.

Alfano, M., \& Skorburg, J. A. (2016). The embedded and extended character hypotheses. In J. Kiverstein (Ed.), The philosophy of the social mind (pp. 465-478). New York, NY: Routledge.

Allport, G. W. (1937). Personality: A psychological interpretation. New York, NY: Holt Rinehart \& Winston.

Ballard, D., Hayhoe, M., Pook, P., \& Rao, R. (1997). Deictic codes for the embodiment of cognition. Behavioral and Brain Sciences, 20, 723-767.

Bernecker, S. (2014). How to understand the extended mind. Philosophical Issues, 24(1), 1-23.

Brooks, R. (1991). Intelligence without representation. Artificial Intelligence, 47, 139-159.

Cantor, N., \& Kihlstrom, J. (1987). Personality and social intelligence. Englewood Cliffs, NJ: Prentice Hall.

Chemero, A. (2011). Radical embodied cognitive science (reprint ed.). Cambridge, MA: Bradford. Clark, A. (2008). Supersizing the mind: Action, embodiment, and cognitive extension. New York, NY: Oxford University Press. 
Clark, A., \& Chalmers, D. (1998). The extended mind. Analysis, 58, 7-19.

Cook, W., \& Kenny, D. (2005). The actor-partner interdependence model: A model of bidirectional effects in developmental studies. International Journal of Behavioral Development, 29, 101-109.

Darley, J., \& Batson, C. D. (1973). "From Jerusalem to Jericho": A study of situational and dispositional variables in helping behavior. Journal of Personality and Social Psychology, 27, 100-108.

Darley, J., \& Fazio, R. (1980). Expectancy confirmation processes arising in the social interaction sequence. American Psychologist, 35, 867-881.

Darley, J., \& Latane, B. (1968). Bystander intervention in emergencies: Diffusion of responsibility. Journal of Personality and Social Psychology, 8, 377-383.

Dewey, J. (1916/2004). Essays in experimental logic. Chicago: Dover.

Doris, J. (2002). Lack of character: Personality and moral behavior. Cambridge: Cambridge University Press.

Doris, J. (2015). Talking to ourselves: Reflection, ignorance, and agency. New York, NY: Oxford University Press.

Funder, D. (2006). Towards a resolution of the personality triad: Persons, situations, and behaviors. Journal of Research in Personality, 40, 21-34.

Funder, D., \& Ozer, D. (1983). Behavior as a function of the situation. Journal of Personality and Social Psychology, 44, 107-112.

Gallagher, S. (2013). The socially extended mind. Cognitive Systems Research, 25-26, 4-12.

Gallagher, S. (2014). Pragmatic interventions into enactive and extended conceptions of cognition. Philosophical Issues, 24, 110-126.

Gallagher, S., \& Crisafi, A. (2009). Mental institutions. Topoi, 28, 45-51.

Harris, C., Keil, P., Sutton, J., Barnier, A., \& McIlwain, D. (2011). We remember, we forget: Collaborative remembering in older couples. Discourse Processes, 48, 267-303.

Heersmink, R. (2015). Dimensions of integration in embedded and extended cognitive systems. Phenomenology and the Cognitive Sciences, 14, 577-598.

Howell, R. J. (2016). Extended virtues and the boundaries of persons. Journal of the American Philosophical Association, 2, 146-163.

Huebner, B. (2013). Socially embedded cognition. Cognitive Systems Research, 25-26, 13-18.

Huebner, B. (2016). Transactive memory reconstructed: Rethinking wegner's research program. The Southern Journal of Philosophy, 54, 48-69.

Hurley, S. (2010). Varieties of externalism. In R. Menary (Ed.), The extended mind (pp. 101153). Cambridge, MA: MIT Press.

Ickes, W., Snyder, M., \& Garcia, S. (1997). Personality influence on the choice of situations. In R. Hogan, J. Johnson, \& S. Briggs (Eds.), Handbook of personality psychology (pp. 165-195). New York, NY: Academic Press.

Jones, E. E. (1986). Interpreting interpersonal behavior: The effects of expectancies. Science, $234,41-46$.

Kashy, D. A., \& Kenny, D. A. (1999). The analysis of data from dyads and groups. In H. T. Reis \& C. M. Judd (Eds.), Handbook of research methods in social psychology (pp. 451-477). New York, NY: Cambridge University Press.

Kenny, D. A. (1996). Models of non-independence in dyadic research. Journal of Social and Personal Relationships, 13, 279-294.

Kihlstrom, J. (2013). The person-situation interaction. In D. Carlston (Ed.), The Oxford handbook of social cognition (pp. 786-806). New York, NY: Oxford University Press.

Kirchhoff, M. (2015). Composition and transactive memory systems. Philosophical Explorations, 19, 59-77. 
Kirsh, D., \& Maglio, P. (1994). On distinguishing epistemic from pragmatic action. Cognitive Science, 18, 513-549.

Lewin, K. (1936/2015). Principles of topological psychology. (F. Heider, Trans.). Eastford, CT: Martino Fine.

Lewin, K. (1939/1951). Field theory and experiment in social psychology: Concepts and methods. In K. Lewin (Ed.), A dynamic theory of personality (pp. 130-154). New York, NY: Harper \& Row.

Lewin, K. (1951). Field theory in social science. New York, NY: Harper.

Lewis, K., \& Herndon, B. (2011). Transactive memory systems: Current issues and future research directions. Organization Science, 22, 1254-1265.

Madzia, R. (2013). Chicago pragmatism and the extended mind theory: Mead and Dewey on the nature of cognition. European Journal of Pragmatism and American Philosophy, 5, 279-297.

Martz, J. M., Verette, J., Arriaga, X. B., Slovik, L. F., Cox, C. L., \& Rusbult, C. E. (1998). Positive illusion in close relationships. Personal Relationships, 5, 159-181.

Mead, G. H. (1934/1962). Mind, self, and society from the standpoint of a social behaviorist. Chicago, IL: University of Chicago Press.

Menary, R. (2007). Cognitive integration: Mind and cognition unbounded. Baskingstoke: Palgrave Macmillan.

Milgram, S. (1974). Obedience to authority: An experimental view. New York, NY: Harper \& Row.

Mischel, W. (1968). Personality and assessment. New York, NY: Wiley.

Mischel, W. (2009). From personality and assessment to personality science. Journal of Research in Personality, 43, 282-290.

Murray, S. L., \& Holmes, J. G. (1997). A leap of faith? Positive illusions in romantic relationships. Personality and Social Psychology Bulletin, 23, 586-604.

Murray, S. L., Holmes, J. G., \& Griffin, D. W. (1996a). The self-fulfilling nature of positive illusions in romantic relationships: Love is not blind, but prescient. Journal of Personality and Social Psychology, 71, 1155-1180.

Murray, S. L., Holmes, J. G., \& Griffin, D. W. (1996b). The benefits of positive illusions: Idealization and the construction of satisfaction in close relationships. Journal of Personality and Social Psychology, 70, 79-98.

Palermos, S. O. (2014). Loops, constitution and cognitive extension. Cognitive Systems Research, 27, 25-41.

Peirce, C. S. (1903/1998). Three normative sciences. In The Peirce Edition Project (Ed.), The essential Peirce: Selected philosophical writings vol. 2(1893-1913) (pp. 196-207). Bloomington, IN: Indiana University Press.

Pöyhönen, S. (2014). Explanatory power of extended cognition. Philosophical Psychology, 27, 735-759.

Ren, Y., \& Argote, L. (2011). Transactive memory systems 1985-2010: An integrative framework of key dimensions, antecedents, and consequences. The Academy of Management Annals, $5,189-229$.

Richard, F. D., Bond, C. F., \& Stokes-Zoota, J. (2003). One hundred years of social psychology quantitatively described. Review of General Psychology, 7, 331-363.

Rockwell, W. T. (2005). Neither brain nor ghost: A non-dualist alternative to the mind-brain identity theory. Cambridge: MIT Press.

Ross, D., \& Ladyman, J. (2010). The alleged coupling-constitution fallacy and the mature sciences. In R. Menary (Ed.), The extended mind (pp. 155-166). Cambridge, MA: MIT Press.

Rowlands, M. (2013). The new science of the mind: From extended mind to embodied phenomenology. Cambridge, MA: MIT Press. 
Rupert, R. (2004). Challenges to the hypothesis of extended cognition. Journal of Philosophy, $101,389-428$.

Skorburg, J. A. (2013). Beyond embodiment: John Dewey and the integrated mind. The Pluralist, 8, 66-78.

Srivastava, S., McGonigal, K., Richards, J., Butler, E., \& Gross, J. J. (2006). Optimism in close relationships: How seeing things in a positive light makes them so. Journal of Personality and Social Psychology, 91, 143-153.

Sterelny, K. (2010). Minds: extended or scaffolded? Phenomenology and the Cognitive Sciences, $9,465-481$.

Sutton, J. (2010). Exograms and interdisciplinarity: History, the extended mind and the civilizing process. In R. Menary (Ed.), The extended mind (pp. 189-225). Cambridge, MA: MIT Press.

Sutton, J., Harris, C. B., Keil, P., \& Barnier, A. J. (2010). The psychology of memory, extended cognition, and socially distributed remembering. Phenomenology and the Cognitive Sciences, 9, 521-560.

Swann, W., \& Seyle, C. (2005). Personality psychology's comeback and its emerging symbiosis with social psychology. Personality and Social Psychology Bulletin, 31, 155-165.

Theiner, G. (2013). Transactive memory systems: A mechanistic analysis of emergent group memory. Review of Philosophy and Psychology, 4, 65-89.

Tollefsen, D., Dale, R., \& Paxton, A. (2013). Alignment, transactive memory, and collective cognitive systems. Review of Philosophy and Psychology, 4, 49-64.

Vaesen, K. (2014). Dewey on extended cognition and epistemology. Philosophical Issues, 24, 426-438.

Wegner, D. (1986). Transactive memory: A contemporary analysis of the group mind. In B. Mullen \& G. R. Goethals (Eds.), Theories of group behavior (pp. 185-208). New York, NY: Springer-Verlag.

Wegner, D. (1995). A computer network model of human transactive memory. Social Cognition, 13, 319-339.

Wegner, D., Erber, R., \& Raymond, P. (1991). Transactive memory in close relationships. Journal of Personality and Social Psychology, 61, 923-929.

Wegner, D., Giuliano, T., \& Hertel, P. (1985). Cognitive interdependence in close relationships. In W. Ickes (Ed.), Compatible and incompatible relationships (pp. 253-276). New York, NY: Springer-Verlag.

Wagman, J., \& Chemero, A. (2014). The end of the debate over extended cognition. In T. Solymosi \& J. Shook (Eds.), Neuroscience, neurophilosophy, and pragmatism: Brains at work with the world (pp. 105-124). New York, NY: Palgrave.

Wilson, R. A., \& Clark, A. (2009). How to situate cognition: Letting nature take its course. In M. Aydede \& P. Robbins (Eds.), The Cambridge handbook of situated cognition (pp. 55-77). Cambridge: Cambridge University Press. 